\title{
A SUCESSÃO DOS COMPANHEIROS NO CÓDIGO CIVIL
}

\section{ARTIGO ORIGINAL}

SANTOS, Caio Oliveira dos ${ }^{1}$

SANTOS, Caio Oliveira dos. A sucessão dos companheiros no Código Civil. Revista Científica Multidisciplinar Núcleo do Conhecimento. Ano 05, Ed. 06, Vol. 01, pp. 182-190. Junho de 2020. ISSN: 2448-0959, Link de acesso: https://www.nucleodoconhecimento.com.br/lei/sucessao-dos-companheiros

\section{RESUMO}

O presente Artigo Jurídico foi elaborado como conclusão da graduação em Direito pelo Centro Universitário Jorge Amado. O tema abordado é de suma importância, pois existia uma insegurança jurídica acerca da sucessão do companheiro(a) no código civil através do art.1790, pois é dever do Estado proteger a Família por expressa previsão constitucional (art. $226 \mathrm{CF} / 88$ ) mas seguindo a orientação da Constituição Federal e da jurisprudência do Supremo Tribunal Federal firmou-se no sentido de equiparar o casamento a União Estável e seu regime sucessório como estabelece o tema 498 do referido tribunal. $O$ presente artigo pretende demonstrar a inconstitucionalidade do art. 1.790 do Código Civil e para tanto adotou-se o procedimento bibliográfico, reunindo uma grande quantidade de livros, artigos, leis e jurisprudências sobre o tema de modo a possibilitar uma melhor compreensão sobre as particularidades dessa sucessão.

\footnotetext{
1 Assessor jurídico na Energia Brasil. Possui graduação em Direito pelo Centro Universitário Jorge Amado (2015). Pós graduado Lato Sensu em Direito e Processo do Trabalho pela LFG em parceria com a Universidade Anhanguera (2016-2017) com Carga Horária de 426 horas. Especialista em Ciências Criminais com Carga Horária de 360 horas(2018-2019). Pós Graduando Lato Sensu em Direito Animal pela Uninter em parceria com a Escola da Magistratura Federal do Paraná (Esmafe).
} 
Palavras-chave: Sucessão do companheiro, proteção da família, regime sucessório, Código Civil, Direito de Família.

\section{INTRODUÇÃO}

O artigo tem por finalidade tratar da inconstitucionalidade do art. 1.790 do Código Civil de 2002, devendo ser aplicado, tanto nas hipóteses de casamento quanto nas de união estável, o regime do art. 1.829 do Código Civil vigente. Havia muita insegurança jurídica sobre a sucessão do(a) companheiro(a), todavia, com o tema 498, o Supremo Tribunal Federal finalmente igualou a família conjugal e a união estável para estabelecer de forma igualitária a sucessão do(a) companheiro(a).

O Supremo chegou a tal decisão tendo em vista o dever do Estado de proteger a família, além da família não se tratar de uma instituição-fim, mas uma instituição-meio para a promoção da dignidade das pessoas que a compõe e para construção de uma sociedade mais justa e igualitária.

Diante disso, toda e qualquer família tem o direito amparado pela Constituição Federal de ser protegida pelo Estado, e este, por sua vez, tem o dever de proporcionar todos os direitos que as famílias fazem jus, independentemente de seu formato e constituição, nos termos do artigo 226 da Constituição Federal de 1988.

O presente artigo será dividido em três seções. A primeira seção refere-se a sucessão como um direito fundamental decorrente do princípio da dignidade da pessoa humana e das formas de interpretação. Ainda com relação as técnicas de interpretação em prol da família constituída por meio da união estável e com a consequente declaração de igualdade de sucessão conjugal.

A segunda seção refere-se a conceituação do termo "Família", o princípio da Pluralidade das entidades Familiares, demonstrando que esse conceito é muito mais amplo do que está expresso na Constituição Federal, devendo ser dada uma interpretação mais extensiva, haja vista aquele rol ser apenas exemplificativo. 
A terceira seção se destina a demonstrar a posição doutrinária no sentido de que o art. 1.790 do Código Civil seria inconstitucional. Entendimento que foi confirmado pela jurisprudência do Supremo Tribunal Federal através do tema 498, pondo fim a qualquer entendimento contrário, promovendo a pacificando o tema.

O método utilizado no referido artigo científico será o método jurídico-sociológico buscando a realização concreta da lei, visando sempre às demandas e necessidades sociais e sua adequação aos institutos jurídicos. Faz-se necessário a utilização desse tipo de pesquisa visto que o tema trabalhado faz parte do direito, uma ciência humana, no qual, "números frios e precisos" podem não trazer a profundidade que se pretende alcançar.

Uma pesquisa abordando o método jurídico- sociológico engloba as necessidades sociais adequando-se aos institutos jurídicos, uma vez que não basta a análise fria da lei. $O$ artigo objetiva trabalhar também a pesquisa documental, com conceitos doutrinários, jurisprudenciais e pela legislação em questão. Assim sendo, o referido artigo tem como utilizar o método jurídico-sociológico na busca de uma pesquisa dinâmica. Demonstrando método, conteúdo e qualidade.

\section{SUCESSÃO COMO DIREITO FUNDAMENTAL A DIGNIDADE DA PESSOA HUMANA}

A sucessão em si em nosso ordenamento jurídico, trata-se de direito fundamental da pessoa humana, uma vez que ao prestigiar o ser humano como sujeito de Direito, reconhece o Direito a Sucessão do "de cujos" com relação a seus sobreviventes. Valor inerente ao nosso Estado Democrático de Direito.

A dignidade humana, pode ser considerado um Fundamento do Estado, em seu art. $1^{0}$ da CF/88, devendo ser seguido em todos os ramos possíveis, temos como exemplo, o Direito Civil, Processual Civil, Direito Penal, todos os ramos do Direito devem estar interligados com a dignidade humana, de uma forma que é um verdadeiro valor, pela vontade constitucional. O Direito das Sucessões assim como o Direito de 
Família, e como os outros ramos do Direito, deverão seguir o valor inerente da dignidade humana, na busca da justiça social.

Devemos então entender os ramos interpretativos do Direito para atribuir um sentido a norma do art. 1790 do Código Civil pois o bom interprete é aquele que consegue interpretar o texto legal[2], não ela por si mesma, mas o seu espírito, as quatro interpretações, surgem como uma forma de entendermos esse sentimento da lei, buscando sempre a intenção do legislador, sendo uma busca por um objetivismo, pela exteriorização dos significados da ordem jurídica.

A interpretação gramatical busca o sentido literal de uma determinada norma jurídica. Ou seja, tentamos entender o que o legislador quis escrever, quais as palavras utilizadas em si. A etimologia da palavra é levada em questão, buscando a origem etimológica e aplicando as regras de concordância ou regência, verbal ou nominal.[3]

Essa técnica é criticada tendo em vista que não devemos apenas nos ater ao que simplesmente está escrito, mas buscar outros meios de interpretação. Caso nos atermos a gramática da norma, cometeremos o erro de sermos positivistas, incompatibilizando com o nosso Estado Constitucional de Direito. A interpretação gramatical deve ater-se sempre aos outros métodos interpretativos em conjunto até formamos o ciclo hermenêutico. A interpretação sistemática por sua vez, analisa o contexto das normas, tendo em vista as outras normas dentro do ordenamento jurídico que é considerado o todo. Uma verdadeira busca inevitável do sentido global num conjunto abarcante, envolvendo sempre uma teleologia, ou seja, uma visão ampla do próprio ordenamento jurídico.[4]

A interpretação sociológica tem por finalidade, entendermos o porquê daquela norma, entender as suas relações sociais originárias, e buscando sempre inovar na futura interpretação, buscar a mesma finalidade que deu origem daquela norma tendo em vista a necessidade atual.

Todos os meios interpretativos reunidos formam o ciclo hermenêutico, muito importante na busca da aplicação correta do Direito tendo em vista, que as técnicas 
reunidas de uma forma clara, atendendo a novas realidades sociais, é importante pois o legislador não consegue acompanhar de forma rápida as mudanças da sociedade, cabe ao interprete o papel de entender através desses métodos a melhor forma possível de aplicar o direito no caso concreto.

Pelo presente artigo a intenção é utilizar as técnicas interpretativas em prol da família formada através da união estável e com a consequente declaração de igualdade de sucessão conjugal com o companheiro do art. 1790 do Código Civil.

\section{CONCEITO DE FAMÍLIA, PRINCÍPIO DA PLURALIDADE DAS ENTIDADES FAMILIARES, UNIÃO ESTÁVEL}

Devemos interpretar a sucessão do companheiro a luz da CF/88 viabilizando-se a União Estável como entidade Familiar, atendendo a realidade social de forma teologicamente com o princípio da igualdade da própria carta magna em seu art. 5ㅇ․ A família é o núcleo existencial integrado por pessoas unidas por vínculo socioafetivo, teologicamente vocacionada a permitir a realização plena dos seus integrantes.[5]

$\mathrm{Na}$ realidade fática quando aparecer situações concretas sobre a sucessão do companheiro frente ao art. 1.790 do Código Civil, a interpretação dada deve ser sempre no sentido de equiparar cônjuges e companheiros, dando-lhes sempre um tratamento isonômico. Essa interpretação se ampara no princípio da Pluralidade das entidades Familiares, tendo uma interpretação teleológica, concisa, clara, atendendo aos fins sociais.

A Entidade Familiar formada a partir da união estável, tem como fundamento as relações intersubjetivas, sendo o afeto a busca de realizações pessoais em busca da felicidade entre ambos os companheiros. $O$ afeto é o caminho para a construção de uma difusão de valores dentro da própria sociedade. Lato senso, o vocábulo família abrange todas as pessoas ligadas por vínculo de sangue e que procedem, portanto, de um tronco ancestral comum, bem como as unidas por afinidade e pela adoção. Compreende os cônjuges e companheiros, os parentes e os afins.[6] 
O texto Constitucional nos faz atermos ao fato de termos em vista princípios importantes, quais sejam, a igualdade Constitucional e o valor universal do ordenamento jurídico, que trata-se à dignidade da pessoa humana(art. 1으 um verdadeiro super princípio, um valor a ser seguido por todo ordenamento jurídico, seja ele constitucional ou infraconstitucional. Devemos então nos ater o Direito das Famílias, adequando a norma as relações intersubjetivas que surgem ao longo do tempo.

Sobre esse preceito constitucional de igualdade, então não deve existir qualquer tipo de discriminação com relação às entidades familiares, tendo em vista o caráter plurifamiliar do Direito das Famílias, sendo assim, não deve existir diferenças com relação a União Estável e o Casamento, sendo que ambos são famílias e devem ser protegidos pelo Estado e por força da Constituição.

Sendo a Constituição uma verdadeira hierarquia de valores, representando a família um desses valores previstos no art. 226, § 3º, ao prever que o Estado deverá proteger as entidades familiares, já na época em que o Código Civil de 1.916 estava em vigência, os princípios ali contidos não eram para ser seguidos, tendo em vista que o Código era anterior à Constituição e consequentemente os princípios constitucionais deveriam prevalecer em face do antigo Código Civil, já que eram incompatíveis.

Código anterior era altamente discriminatório, estabelecendo diferenças entre homem e mulher, atribuindo a união estável o caráter de concubinato, discriminando os filhos fora da relação do casamento. Todo esse tratamento discriminatório é inaceitável pela Constituição Federal de 1988.

Seria inviável não conceder direitos sucessórios a União Estável, ou até mesmo, propor dificuldades pelo fato de o Estado proteger as famílias de uma maneira geral, a União estável é uma família convivencional e sendo assim, deve-se reconhecer o Direito à sucessão do Companheiro(a). 


\section{POSIÇÃO DOUTRINARIA E JURISPRUDENCIAL SOBRE A CONSTITUCIONALIDADE DO ARTIGO 1.790}

É exatamente por isso, de se perceber a inconstitucionalidade da norma legal que regulamenta o direito sucessório do companheiro (art. 1.790 do Código Civil de 2002, que defere proteção sucessória ao companheiro de maneira inferior aos direitos garantidos ao cônjuge), por estar divorciada da efetiva proteção da pessoa humana, negando a sua plena realização e dignidade e, por conseguinte, afrontando a Lei Maior.[7]

A solução prática apontada para a doutrina seria o interessado ao propor a ação de herança pedir a inconstitucionalidade do art. 1.790 do Código Civil em Controle Difuso de constitucionalidade, tendo em vista a tese de que o companheiro deve ter direito a Sucessão sem limitações dos incisos do art. 1.790 do Código Civil.

Deve-se proceder, assim, com o questionamento ao tratamento do companheiro como herdeiro necessário, garantindo a legítima no valor de 50\% do patrimônio líquido do seu falecido convivente tendo em vista a abertura da sucessão, com a morte do "de cujos".[8]

Segundo Jurisprudência recente do Supremo Tribunal Federal, por intermédio do tema 498, pacificou a matéria ao declarar inconstitucional a distinção de regimes sucessórios entre cônjuges e companheiros prevista no art. 1.790, devendo ser aplicado tanto para o casamento quanto para a União Estável o regime previsto no art. 1.829 do Código Civil, ou seja, o direito da sucessão entre companheiros passou a ser o mesmo atribuído aos cônjuges, decisão de 2017 trazendo segurança jurídica.

O Supremo Tribunal Federal ressaltou que distinguir direitos sucessórios entre as famílias formadas através da União Estável e a família formada por meio do casamento violaria o princípio da igualdade das famílias, da dignidade humana, da proporcionalidade. 


\section{CONCLUSÃO}

Ao longo do presente artigo buscou-se tratar sobre a inconstitucionalidade do art. 1.790 do Código Civil tendo em vista os métodos interpretativos a luz da Constituição, os princípios constitucionais da igualdade das famílias, da dignidade humana, proporcionalidade, pluralidade das entidades familiares, o tema 498 do STF, o dever do Estado de proteger a Família, o Direito das Sucessões como um Direito Fundamental.

A proteção familiar destinada à instituição denominada União Estável, amparado pelo princípio da pluralidade das entidades familiares que está positivado no art. 226 da $\mathrm{CF} / 88$, merece igual proteção jurídica que é destinada à entidade familiar matrimonial tendo em vista que o rol previsto é meramente exemplificativo e tem por finalidade proteção a todas as famílias pelo Estado.

Por consequência, em um Estado Democrático de Direito não se pode admitir qualquer tipo de discriminação da família constituída por meio de união estável em comparação com a família matrimonial tendo em vista o mandamento interpretativo da própria Carta Magna de proteção de toda e qualquer entidade familiar.

Neste contexto o STF através de controle de constitucionalidade através do tema 498 entendeu o que a doutrina há muito tempo já defendia pela aplicação do regime do art. 1829 do Código civil de 2002 tanto nos regimes sucessórios para a União Estável como para o companheiro, não havendo mais qualquer dúvida no que diz respeito a inconstitucionalidade do art. 1790 do Código Civil.

\section{REFERÊNCIAS}

AMORIM, Sebastião Luiz; OLIVEIRA, Euclides Benedito de. Inventário e partilhas: direito das sucessões teoria e prática. 16. Ed. São Paulo(SP): LEUD,2003.

CAHALI, Francisco José; HIRONAKA, Giselda Maria Fernandes Novaes. Direito das Sucessões. São Paulo(SP): Revisto dos Trinais, 2007. 
DIAS, Maria Berenice. Manual de Direito das Famílias. São Paulo(SP): ED. Revista dos Tribunais, 2007.

DINIZ, Maria Helena. Curso de Direito Civil Brasileiro: volume 6: Direito das Sucessões. São Paulo(SP): Saraiva, 2004.

FARIAS, Cristiano Chaves de; ROSENVALD, Nelson. Direito das Famílias. Rio de Janeiro: Lumen Juris,2010.

GONÇALVES, Carlos Roberto. Direito Civil brasileiro, volume 7: direito das sucessões. São Paulo(SP): Saraiva, 2011.

SOARES, Ricardo Maurício Freire. Hermenêutica Jurídica. São Paulo(SP): Saraiva, 2013.

SUPREMO TRIBUNAL FEDERAL. Recurso Extraordinário $n^{\circ} 646721$. Disponívelem<http://www.stf.jus.br/portal/jurisprudenciaRepercussao/verAndamento Processo .asp ?incidente $=4100069$ \& numeroProcesso $=646721 \&$ classeProcesso $=$ RE \& numeroTema=498\#>Acesso em:17 Dezembro 2019.

\section{APÊNDICE - REFERÊNCIAS DE NOTA DE RODAPÉ}

2. SOARES, Ricardo Maurício Freire. Hermenêutica Jurídica. São Paulo(SP): Saraiva, 2013. p.39.

3. Idem. p.32.

4. Idem

5. GAGLIANO, Pablo Stolze; PAMPLONA FILHO, Rodolfo. Novo curso de direito civil: direito de família. 2. ed. ver., atual. e ampl. São Paulo: Saraiva, 2012, p. 43.

6. GONÇALVES, Carlos Roberto. Direito Civil brasileiro, volume 7: direito das sucessões. São Paulo(SP): Saraiva, 2011. p.17. 
7. FARIAS, Cristiano Chaves de; ROSENVALD, Nelson. Direito das Famílias. Rio de Janeiro: Lumen Juris,2010. p. 432.

8. Idem. p.429.

Enviado: Abril, 2020.

Aprovado: Junho, 2020. 